\title{
Coexpression of Glucose Transporters and Glucokinase in Xenopus Oocytes Indicates That Both Glucose Transport and Phosphorylation Determine Glucose Utilization
}

\author{
Hiroshi Morita, ${ }^{\star}$ Yutaka Yano, ${ }^{\$}$ Kevin D. Niswender, $\$$ James M. May, ${ }^{\ddagger}$ Richard R. Whitesell, $\$$ Lan Wu, ${ }^{\star}$ Richard L. Printz, $\$$ \\ Daryl K. Granner, ${ }^{5}$ Mark A. Magnuson, ${ }^{5}$ and Alvin C. Powers*\|l \\ Divisions of *Endocrinology and ${ }^{\ddagger}$ Diabetes, Department of Medicine, Vanderbilt University School of Medicine, Nashville, Tennessee \\ 37232; ${ }^{8}$ Department of Molecular Physiology and Biophysics, Vanderbilt University School of Medicine, Nashville, Tennessee 37232; \\ and "Department of Veterans Affairs Medical Center, Nashville, Tennessee 37232
}

\begin{abstract}
A Xenopus oocyte expression system was used to examine how glucose transporters (GLUT 2 and GLUT 3) and glucokinase (GK) activity affect glucose utilization. Uninjected oocytes had low rates of both glucose transport and phosphorylation; expression of GLUT 2 or GLUT 3 increased glucose phosphorylation $\sim 20$-fold by a low $K_{\mathrm{m}}$, endogenous hexokinase at glucose concentrations $\leq 1 \mathrm{mM}$, but not at higher glucose concentrations. Coexpression of functional GK isoforms with GLUT 2 or 3 increased glucose utilization approximately an additional two- to threefold primarily at the physiologic glucose concentrations of 5-20 mM. The $K_{m}$ for glucose of both the hepatic and beta cell isoforms of GK, determined in situ, was $\sim 5-10 \mathrm{mM}$ when coexpressed with either GLUT 2 or GLUT 3. The increase in glucose utilization by coexpression of GLUT 3 and GK was dependent upon glucose phosphorylation since two missense GK mutations linked with maturity-onset diabetes, 182:Val $\rightarrow$ Met and 228:Thr $\rightarrow$ Met, did not increase glucose utilization despite accumulation of both a similar amount of immunoreactive GK protein and glucose inside the cell. Coexpression of a mutant GK and a normal GK isoform did not interfere with the function of the normal GK enzyme. Since the coexpression of GK and a glucose transporter in oocytes resembles conditions in the hepatocyte and pancreatic beta cell, these results indicate that increases in glucose utilization at glucose concentrations $>1 \mathrm{mM}$ depend upon both a functional glucose transporter and GK. (J. Clin. Invest. 1994. 94:13731382.) Key words: glucose • hexokinase • glucose transport - pancreatic islet $\cdot$ glucokinase
\end{abstract}

\section{Introduction}

The initial step in glucose utilization in mammalian cells is the movement of glucose across the plasma membrane by diffusion via a family of facilitative glucose transporters (GLUT 1-5). ${ }^{1}$

Address correspondence to Alvin C. Powers, Division of Endocrinology, AA 4206, MCN, Vanderbilt University, Nashville, TN 37232.

Received for publication 8 November 1993 and in revised form 24 May 1994.

1. Abbreviations used in this paper: GK, glucokinase; GLUT, glucose transporter; HK, hexokinase; MODY, maturity-onset diabetes of the young; TEA, triethanolamine.

The Journal of Clinical Investigation, Inc

Volume 94, October 1994, 1373-1382
This is followed by the phosphorylation of glucose on the sixth carbon position by a family of hexokinases (HK types I-IV) $(1,2)$. The five different mammalian glucose transporters and four different hexokinases that have been identified constitute two different gene families whose members display distinctive tissue distributions and kinetic properties. Although distinct processes, glucose transport and phosphorylation are functionally paired since the kinetic properties of the specific glucose transporter or hexokinase present in a given cell may influence the overall rate of glucose utilization. The relative contribution of either process to glucose utilization may vary from tissue to tissue. For instance, in the pancreatic beta cell and hepatocyte the rate of glucose utilization is determined by the amount of glucokinase (HK IV), since the $V_{\max }$ of glucose phosphorylation is less than that of glucose transport (3). In contrast, the rate of glucose utilization in fat appears to be determined largely at the level of glucose transport, as insulin stimulation of transport increases glucose phosphorylation by the hexokinase present in adipocytes (4).

The functional pairing of glucose transport and phosphorylation may explain why certain glucose transporters and hexokinases are coexpressed in a tissue-specific pattern and why high affinity transporters are coexpressed with high affinity hexokinases and low affinity transporters with low affinity hexokinases. For example, the pancreatic beta cell and the liver coexpress the low affinity GLUT 2 and the low affinity glucokinase (HK IV), while skeletal muscle and fat coexpress the high affinity GLUT 1/GLUT 4 and the high affinity HK II, and the brain coexpresses the high affinity GLUT 1/GLUT 3 and the high affinity HK I $(1,5)$. Although the functional pairing of glucose transport and phosphorylation may be important in determining the rate of glucose utilization, it has been difficult to independently ascertain the relative contribution of each process to glucose utilization in different mammalian cells. Most studies have focused on either transport or phosphorylation in isolation, and it has not been possible to examine the interaction of particular transporters and hexokinases.

In this study we examined the functional importance of glucose transporter and glucokinase activity on glucose utilization in a Xenopus oocyte expression system. This is an important issue since glucokinase (GK) is thought to determine glucose usage by both the pancreatic beta cell and the hepatocyte (3). Glucose-stimulated insulin secretion by the beta cell correlates with the rate of glucose utilization, and the rate-limiting determinant in this process is GK $(3,6)$. Moreover, GK gene mutations have been associated recently with a familial form of early onset non-insulin-dependent diabetes mellitus known as maturity-onset diabetes of the young (MODY) that is characterized by the development of hyperglycemia early in life, disease 
transmission in an autosomal dominant manner, and reduced glucose-stimulated insulin secretion (7-13). Gidh-Jain et al. (14) have shown that most diabetes-linked GK mutants, when expressed in bacteria, have either a reduced $V_{\max }$ or affinity for glucose, thus suggesting that the diabetes in these pedigrees is due to the altered kinetic properties of the enzyme. We have tested this hypothesis further by examining the effect of GK mutations on glucose utilization and GK protein stability in an intact eukaryotic cell. In addition, we have examined the effect of coexpressing a mutant GK protein in the presence of a normal GK isoform to determine whether the autosomal dominant mode of inheritance of diabetes in pedigrees with GK gene mutations is solely due to a gene dosage phenomenon.

\section{Methods}

Materials. The radioisotopes 3-O- $\left[{ }^{3} \mathrm{H}\right]$ methyl-D-glucose $(87.6 \mathrm{Ci} / \mathrm{mmol})$ and $\left[2-{ }^{3} \mathrm{H}\right]$ glucose $(22.8 \mathrm{Ci} / \mathrm{mmol})$ were from New England Nuclear (Boston, MA). Phloretin and 3-O-methylglucose were from Aldrich Chemical Co. (Milwaukee, WI). In vitro RNA transcription and translation reaction kits were from Stratagene (La Jolla, CA) and Promega Corp. (Madison, WI), respectively. Taq polymerase and PFU DNA polymerase were from Perkin Elmer Corp. (Norwalk, CT) and Stratagene. Resin AG 1-X8, CI, and Poly-prep column were from Bio-Rad Laboratories (Richmond, CA). Oligonucleotides were synthesized in the Vanderbilt Diabetes Center DNA Core laboratory.

Isolation and microinjection of Xenopus oocytes. Female Xenopus laevis (Xenopus I, Ann Arbor, MI) were maintained in a 12-h light cycle at $20^{\circ} \mathrm{C}$ and fed a diet of minced bovine liver. Frogs were anesthetized by immersion in $0.15 \%$ 3-aminobenzoic acid ethyl ester (Sigma Immunochemicals, St. Louis, MO) before removing ovarian fragments by a lateral ventral incision. The tissue fragments were rinsed in OR-2 (82.5 $\mathrm{mM} \mathrm{NaCl}, 2 \mathrm{mM} \mathrm{KCl}, 1 \mathrm{mM} \mathrm{MgCl} 2,5 \mathrm{mM}$ Hepes, $\mathrm{pH} \mathrm{7.5),} \mathrm{incubated}$ on a circular rotator in OR-2 containing $4 \mathrm{mg} / \mathrm{ml}$ of collagenase type II (Worthington Biochemical Corp., Freehold, NJ) for $2 \mathrm{~h}$ at room temperature. Healthy oocytes were selected under a dissection microscope, maintained at $18^{\circ} \mathrm{C}$ in $\mathrm{OR}$ medium $(82.5 \mathrm{mM} \mathrm{NaCl}, 2 \mathrm{mM} \mathrm{KCl}$, $1.8 \mathrm{mM} \mathrm{CaCl}_{2}, 1 \mathrm{mM} \mathrm{MgCl}_{2}, 5 \mathrm{mM}$ Hepes, $\mathrm{pH}$ 7.5) supplemented with penicillin-G/streptomycin (1\%; Gibco Laboratories, Grand Island, NY), and injected within a day of isolation. Oocytes were microinjected with RNA using a Picospritzer II (General Valve Corp., Fairfield, NJ) and a micromanipulator from Singer Instruments Company (Somerset, United Kingdom). Injection volumes were calculated using an eyepiece micrometer and based on the volume of the microinjection drop. After microinjection of RNA, the oocytes were incubated at $18^{\circ} \mathrm{C}$ for $2-4 \mathrm{~d}$, during which time the OR medium was changed daily and any unhealthy oocytes were removed.

RNA synthesis from cDNA templates. The cDNAs encoding the human glucose transporters, GLUT 2 and GLUT 3 (from Dr. Graeme Bell, University of Chicago, Chicago, IL) (15), rat liver GK (16), and human islet GK (from Dr. Alan Permutt, Washington University, St. Louis, MO) (17) were subcloned into a modified oocyte expression vector (pGOV-B) containing 79 bp of 5'- and 204 bp of 3'-untranslated region of Xenopus beta-globin mRNA (original vector provided by Dr. Doug Melton, Harvard University, Boston, MA). All wild-type GLUT and GK cDNAs were prepared by PCR so that they included only the coding region of the cDNA. The normal human islet GK cDNA (17) served as the template for site-specific mutagenesis by the method of Kunkel (18) using 21-bp mutagenic oligonucleotides with the altered base at position 11. All mutations were confirmed by DNA sequence analysis. The corresponding cDNAs were linearized downstream of the $3^{\prime}$ globin untranslated region and transcribed in vitro into capped RNA by T7 RNA polymerase (mRNA capping kit; Stratagene). The yield of the in vitro transcription was assessed by spectrophotometry at $260 \mathrm{nM}$. Verification of full-length transcription of the cDNA was confirmed by electrophoresis on a formaldehyde-agarose gel. RNA for microinjection was dissolved in diethylpyrocarbonate-water at a concentration of $2 \mu \mathrm{g} /$ $\mu \mathrm{l}$ and stored at $-70^{\circ} \mathrm{C}$.

Expression of glucose transporters and GK. Increasing concentrations of GLUT 2 or GLUT 3 mRNA were injected into oocytes, and glucose transport and phosphorylation were measured. $20 \mathrm{ng}$ of GLUT 2 or GLUT 3 RNA produced equivalent levels of glucose transport in the oocyte; GLUT 3 was used for most studies. For coexpression studies, $20 \mathrm{ng}$ of GLUT 2 or $3 \mathrm{mRNA}$ and $40 \mathrm{ng}$ of GK mRNA in a total volume of $30 \mathrm{nl}$ were injected into each oocyte. For coexpression experiments of wild-type and mutant GK, the 30 -nl volume contained $20 \mathrm{ng}$ of glucose transporter mRNA, $20 \mathrm{ng}$ of wild-type GK mRNA and $20 \mathrm{ng}$ of mutant GK mRNA (or an unrelated, capped RNA as a control). For the assay of GK in the homogenate and for immunoblot analysis, $40 \mathrm{ng}$ of GK mRNA was injected. All kinetic analyses were performed in 5-10 oocytes $2 \mathrm{~d}$ after injection of mRNA.

Glucose transport activity. Glucose transport was measured by incubating 5-10 oocytes in $200 \mu \mathrm{l}$ of OR medium with $1.2 \mu \mathrm{Ci}$ of 3-O$\left[{ }^{3} \mathrm{H}\right]$ methyl-D-glucose in $1 \mathrm{mM} 3-O$-methyl glucose for 1 and $30 \mathrm{~min}$. Glucose uptake was terminated by washing the oocytes four times in ice cold OR with $0.2 \mathrm{mM}$ phloretin, and the amount of glucose transport was calculated after liquid scintillation counting.

GK activity measurements. Glucose phosphorylation in intact oocytes was assessed by measuring the ability of GK or HK to phosphorylate $\left[2-{ }^{3} \mathrm{H}\right]$ glucose $(19-21)$. As shown previously, transfer of the $\left[{ }^{3} \mathrm{H}\right]$ label from the 2 position of glucose-6-phosphate to water by phosphoglucose isomerase is quantitative in oocytes (21). The water then diffuses out of the cell. The amount of ${ }^{3} \mathrm{H}_{2} \mathrm{O}$ produced therefore represents the glucose phosphorylating activity, assuming that no $\left[{ }^{3} \mathrm{H}\right]$ glucose-6phosphate is incorporated into glycogen or lactate. This type of assay has been validated for measurements of GK activity in islets (22). In oocytes, we found no $\left[{ }^{3} \mathrm{H}\right]$ in glycolytic intermediates beyond glucose6-phosphate, and none of the label from the $\left[2-{ }^{3} \mathrm{H}\right]$ glucose was found in the glycogen fraction (reference 21 and data not shown). Measurements were performed by incubating the oocytes in $300 \mu \mathrm{l}$ of OR containing $1 \mu \mathrm{Ci}$ of $\left[2{ }^{3} \mathrm{H}\right]$ glucose and unlabeled glucose at concentrations of 0.1-40 mM. After a 3-h incubation with glucose, a 100- $\mu$ l aliquot of the oocyte medium was fixed with isopropanol and applied to a $0.2 \mathrm{ml}$ Dowex AG1-X8 column (converted to the borate form by extensive washing with $1 \mathrm{~N} \mathrm{NaOH}$ followed by $0.3 \mathrm{M}$ boric acid) to separate the ${ }^{3} \mathrm{H}_{2} \mathrm{O}$ from the $\left[2-{ }^{3} \mathrm{H}\right]$ glucose (19). Tritiated water was eluted with two $0.5-\mathrm{ml}$ aliquots of water, and $\left[2-{ }^{3} \mathrm{H}\right]$ glucose was eluted with two 0.5 -ml additions of $1 \mathrm{~N} \mathrm{HCl}$. The amount of ${ }^{3} \mathrm{H}_{2} \mathrm{O}$ was quantitated by liquid scintillation counting. The rate of ${ }^{3} \mathrm{H}_{2} \mathrm{O}$ production in this assay was linear for up to $20 \mathrm{~h}$ (data not shown).

To measure the intracellular glucose concentration, oocytes were incubated with $\left[2-{ }^{3} \mathrm{H}\right]$ glucose in $1-20 \mathrm{mM}$ glucose for $6 \mathrm{~h}$ and then quickly rinsed three times in OR medium (21). The oocytes were then transferred to a scintillation vial containing fresh $O R$ and incubated for $24 \mathrm{~h}$. After the 24-h incubation period, the oocytes were removed from the $\mathrm{OR}$ medium, and the amount of radioactivity remaining in the $O R$ medium was taken to represent the intracellular glucose at the end of the incubation with the various glucose concentrations. The rationale for this assumption is as follows: since the amount of tritiated water and tritiated metabolites retained in the oocyte is extremely low (not shown), and since the only product of $\left[2-{ }^{3} \mathrm{H}\right]$ glucose metabolism in the oocytes is ${ }^{3} \mathrm{H}_{2} \mathrm{O}$, the intracellular glucose at the end of the initial 6-h incubation will be the sum of ${ }^{3} \mathrm{H}_{2} \mathrm{O}$ and $\left[2-{ }^{3} \mathrm{H}\right]$ glucose (representing efflux of unmetabolized glucose from the oocyte). The intracellular glucose space was taken to be the same as that of 3-O-methyl-D-glucose, which was determined in separate experiments by measuring the distribution space in the oocyte of 3-O-[3] ${ }^{3} \mathrm{methyl}-\mathrm{D}-$ glucose. The methylglucose space and the water space of the oocytes averaged $0.25-0.3 \mu$ l over a range of glucose concentrations in oocytes expressing either GLUT 2 or GLUT 3 and GK.

To measure GK activity in a broken cell assay, groups of one to seven oocytes, which had been coinjected with GLUT 3 and GK, were homogenized in $100 \mu \mathrm{l} /$ oocyte of $50 \mathrm{mM}$ triethanolamine (TEA) (pH 7.3), $100 \mathrm{mM} \mathrm{KCl}, 1 \mathrm{mM}$ DTT, 5\% glycerol, $1 \mathrm{mM}$ EGTA, $1 \mathrm{mM}$ 
EDTA, $1 \mathrm{mM}$ PMSF, $1 \mu \mathrm{g} / \mathrm{ml}$ pepstatin A, $1 \mu \mathrm{g} / \mathrm{ml}$ leupeptin, $0.02 \%$ $\mathrm{Na}$ azide, $0.5 \%$ Triton $\mathrm{X}-100$ (pH 7.3), and $20 \mu \mathrm{l} /$ oocyte of $25 \%$ polyethylene glycol. The homogenate was placed on ice for $15 \mathrm{~min}$ and then centrifuged at $12,000 \mathrm{~g}$ for $5 \mathrm{~min}$ at $4^{\circ} \mathrm{C}$. A $120-\mu \mathrm{l}$ aliquot of the supernatant was incubated with a solution of $380 \mu \mathrm{l}$ of $50 \mathrm{mM}$ TEA, $20 \mathrm{mM} \mathrm{MgCl}_{2}, 100 \mathrm{mM} \mathrm{KCl}, 1 \mathrm{mM}$ DTT, $10 \mathrm{mM}$ ATP (pH 8.0-8.3), $0.1 \mu \mathrm{Ci}\left[2{ }^{3} \mathrm{H}\right]$ glucose, and $0.6 \mu \mathrm{g} / \mathrm{ml}$ phosphoglucose isomerase (Sigma Immunochemicals). After a 3-h incubation, $250 \mu \mathrm{l}$ of the incubation medium was removed, fixed with isopropanol, and applied to the borate resin column. The ${ }^{3} \mathrm{H}_{2} \mathrm{O}$ present was eluted from the column and quantitated by liquid scintillation counting.

The $V_{\max }$ and $K_{\mathrm{m}}$ for glucose of HK and GK were determined by Hanes plot analysis and linear regression. To derive the glucose phosphorylating activity in intact oocytes, either the total HK activity or the GK-specific activity (the activity of oocytes expressing both GLUT and GK minus the activity of oocytes expressing only the GLUT) was calculated. Each experiment is the mean activity of a group of seven to eight oocytes incubated for $3 \mathrm{~h}$ in each glucose concentration. Data are presented as mean \pm standard error of at least three different experiments.

Immunoblot analysis. Groups containing 10 oocytes each were homogenized in $50 \mu$ l of a solution of $50 \mathrm{mM}$ TEA (pH 7.3), $100 \mathrm{mM}$ $\mathrm{KCl}, 1 \mathrm{mM}$ DTT, 5\% glycerol, $1 \mathrm{mM}$ EDTA, $1 \mathrm{mM}$ EGTA, $1 \mathrm{mM}$ PMSF, $1 \mu \mathrm{g} / \mathrm{ml}$ pepstatin A, $1 \mu \mathrm{g} / \mathrm{ml}$ leupeptin, $0.02 \% \mathrm{Na}$ azide, $0.5 \%$ Triton X-100, and $10 \mu \mathrm{l}$ of $25 \%$ polyethylene glycol. The homogenate was placed on ice for $15 \mathrm{~min}$ and centrifuged at $12,000 \mathrm{~g}$ for $5 \mathrm{~min}$ at $4^{\circ} \mathrm{C}$. $20 \mu \mathrm{l}$ of the supernatant (representing four injected oocytes per lane) was resolved on $10 \%$ SDS-PAGE and electroblotted onto a polyvinyldifluoride membrane (Immobilon-P; Millipore Corp., Bedford, MA). Nonspecific antibody binding was blocked by incubation in 5\% nonfat powdered milk in Tris-buffered saline with $0.05 \%$ Tween 20 . The membrane was then incubated with a 1:1,000 dilution of a sheep polyclonal GK antiserum produced against a glutathione- $S$-transferase-GK fusion protein $(22,23)$. Antibody binding was detected with goat anti-sheep serum (Calbiochem-Novabiochem Corp., La Jolla, CA) conjugated to alkaline phosphatase and subsequent color development. The intensity of the GK bands was determined by densitometric scanning.

\section{Results}

Effects of glucose transporter and GK expression on glucose utilization by Xenopus oocytes. Uninjected or sham-injected oocytes contain an endogenous HK, but have very low levels of baseline glucose transport and thus a low rate of glucose utilization. Injection of increasing amounts of GLUT 2 or GLUT 3 RNA per oocyte increased both glucose uptake, measured by the accumulation of 3-O-methylglucose in the cell (Fig. $1 \mathrm{~A}$ ), and the utilization of glucose, measured by the production of ${ }^{3} \mathrm{H}_{2} \mathrm{O}$ (Fig. $1 \mathrm{~B}$ ). The rate of glucose uptake and utilization plateaued with 5 ng of RNA per. oocyte and did not increase significantly with the injection of up to $20 \mathrm{ng}$ of RNA. The increase in ${ }^{3} \mathrm{H}_{2} \mathrm{O}$ production by expression of GLUT 2 or GLUT 3 occurred primarily at glucose concentrations $\leq 1 \mathrm{mM}$ (Fig. $2 A$ ). These results indicate that glucose transport is the ratelimiting step in glucose utilization in uninjected or sham-injected oocytes.

Coinjection of RNA encoding the hepatic or islet GK isoform and GLUT 2 or GLUT 3 RNA resulted in a two- to threefold further increase in the rate of glucose utilization, primarily at glucose concentrations $>1 \mathrm{mM}$ (Fig. $2 A-C$ ). Expression of GK alone (no glucose transporter) did not increase glucose transport or glucose utilization (data not shown). Measurements of intracellular and extracellular glucose in oocytes injected with glucose transporter RNA only, or oocytes injected with both transporter and GK RNA, were identical (Fig. $3 A$ ). Glucose accumulation (measured 1 and $30 \mathrm{~min}$ after addition of 3-O- $\left[{ }^{3} \mathrm{H}\right]-$ methyl-D-glucose) was not affected by the coexpression of GK and GLUT 3 (Fig. $3 \mathrm{~B}$ ). Thus, for all calculations shown in Figs. 2 and 4, the glucose concentration plotted on the $\mathrm{x}$-axis is the extracellular glucose concentration since intracellular and extracellular glucose concentrations are equal. Similar HK and GK activities were obtained with either GLUT 2 or GLUT 3 (Fig. 1 and data not shown). These results indicate that in GLUT 2- or GLUT 3-expressing oocytes glucose phosphorylation is the rate-limiting step in glucose utilization.

Analysis of GK activity in Xenopus oocytes. When examined in the oocyte system, the in situ kinetic properties of rat liver GK and human islet GK are similar to those found in normal islets or liver (references 24 and 25 and Table I). In the oocyte system, the rat liver GK and human islet GK were quite similar in their affinity for glucose (5.75 mM compared with $8.3 \mathrm{mM}$ ), and under conditions of maximal GK expression in the oocytes the $V_{\max }$ of the rat liver GK was slightly greater than that of the human islet GK (Table I). The $K_{\mathrm{m}}$ values for GK expressed in the oocyte system are similar to those determined by in situ measurements of GK in hepatocytes and islets and to those obtained with recombinant GK produced by prokaryotic and eukaryotic expression $(24,25)$. Our results differ from those reported previously in which the rat islet GK isoform had a greater $V_{\max }$ than the rat hepatic GK isoform when expressed in either a eukaryotic or prokaryotic expression system (25). Whether these small differences in $K_{\mathrm{m}}$ and $V_{\max }$ relate to minor amino acid differences in the amino terminus of the hepatic and islet forms of GK, to species differences, or to differences in translational efficiency between the islet and liver GK RNA is unknown. Xenopus oocytes possess an endogenous HK activity with a much lower $K_{\mathrm{m}}(0.51 \mathrm{mM})$ for glucose than GK (Fig. 2 $C$ and Table I).

In addition to the in situ measurement of the GK $K_{\mathrm{m}}$ for glucose and $V_{\max }$, the oocytes were homogenized to further study GK enzymatic activity in a broken cell assay. Under these conditions the $K_{\mathrm{m}}$ of the human islet GK was similar while the $V_{\max }$ was $\sim 13$ times higher in the homogenate than in the intact oocytes (Fig. 4 and Table I). A similar observation was noted when HK II was expressed in the oocyte system in that HK II activity was 5-10 times greater in the oocyte homogenate than in the intact oocyte assay (data not shown). The apparent increase in HK or GK is not due to activation of the enzyme during homogenization since purified HK II is not activated by the homogenization procedure (data not shown). A similar difference between HK activity in intact pancreatic islets versus pancreatic islet homogenate has been noted previously $(26,27)$. The reason for the greater amount of GK activity in the oocyte homogenate compared with the intact oocyte assay is unclear, but it is possible that there is compartmentalization of GK in intact oocytes to a location that is not accessible to glucose and that homogenization releases the enzyme. Compartmentalization of glucose transporters has been noted in the oocyte system with the majority of glucose transporters located intracellularly and only a small percentage in the plasma membrane $(28,29)$. An alternative possibility is that homogenization removes GK or HK II from inhibition by an intracellular regulator such as glucose-6-phosphate. However, since GK is not inhibited by glucose-6-phosphate, this seems less likely.

Analysis of GK missense mutants. The glucose phosphorylating activity of three diabetes-linked, human islet GK mutants was tested by coexpression with GLUT 2 and GLUT 3 in both intact and homogenized oocytes. Two of the GK mutants had 

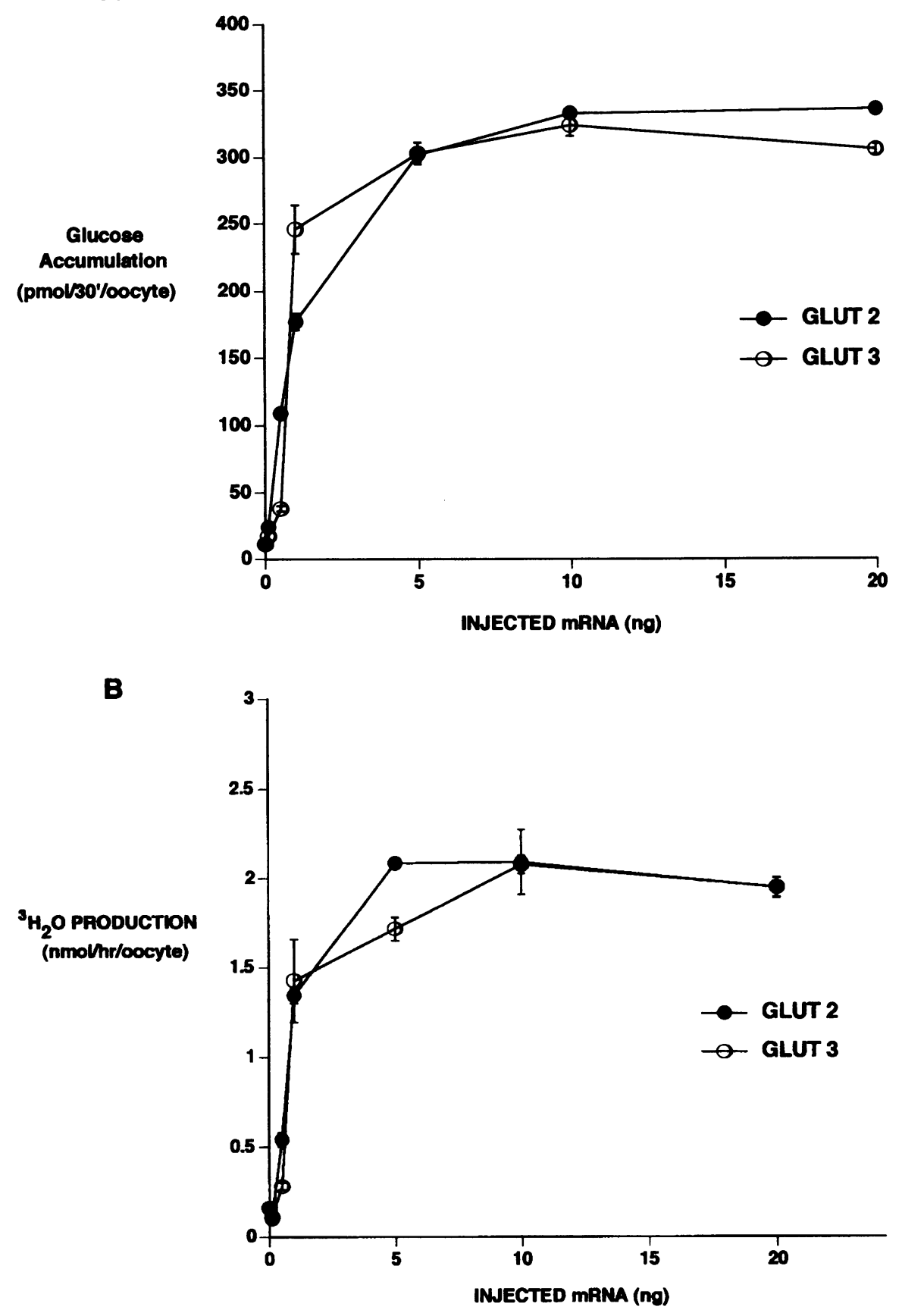

Figure 1. RNA dose-response of glucose transport and glucose utilization. Oocytes were microinjected with increasing concentrations of GLUT 2 or GLUT 3 mRNA, and glucose transport and phosphorylation were measured. $(A)$ The accumulation of 3-O$\left[{ }^{3} \mathrm{H}\right]$ methyl-D-glucose $(1 \mathrm{mM})$ by oocytes injected with either GLUT 2 or GLUT 3 mRNA was measured after a 30-min incubation as described in Methods. (B) Glucose phosphorylating activity $\left({ }^{3} \mathrm{H}_{2} \mathrm{O}\right.$ production rate from $\left[2-{ }^{3} \mathrm{H}\right]$ glucose in nanomoles/hour/ oocyte) of oocytes injected with either GLUT 2 or GLUT 3 was measured as described in Methods. Each point represents mean \pm SEM of separate experiments with 5-10 oocytes/ determination.

a low level of enzymatic activity, but one GK mutant had enzymatic activity that closely resembled wild-type GK. The ${ }^{3} \mathrm{H}_{2} \mathrm{O}$ production rate of the mutants 182: $\mathrm{Val} \rightarrow$ Met and 228: $\mathrm{Thr} \rightarrow$ Met, was markedly reduced compared with the wild-type GK (Fig. $4, A$ and $B$ and Table I). In the intact oocyte assay, no GK activity was detected for either the $182: \mathrm{Val} \rightarrow$ Met mutant or the 228:Thr $\rightarrow$ Met mutant. Because the GK activity is much greater in the homogenized oocyte assay (note the difference in tritiated water production between Fig. $4 A$ and $B$ and see results under Analysis of GK activity in Xenopus oocytes, above), a low level of enzymatic activity for the $182: \mathrm{Val} \rightarrow$ Met mutant was detectable in the oocyte homogenate assay. However, the enzymatic activity of the 228:Thr $\rightarrow$ Met mutant was so low that an accurate
$V_{\max }$ or $K_{\mathrm{m}}$ could not be determined in either GK assay (Fig. 4, $A$ and $B$ and Table I). A third mutant, GK 300:Glu $\rightarrow$ Lys, had a similar $V_{\max }$ and $K_{\mathrm{m}}$ to the wild-type enzyme in the intact oocyte assay, but a slightly higher $K_{\mathrm{m}}$ in the homogenate GK assay (Table I).

Immunoblot analysis of GK protein. To determine whether this reduced level of GK activity in oocytes expressing a mutant GK as compared with wild-type GK resulted from a reduced level of mutant GK protein, the amount of GK protein in a $12,000 \mathrm{~g}$ supernatant prepared from oocytes injected with both normal and mutant GK mRNAs was analyzed by Western blot analysis. Comparable amounts of wild-type and mutant GK protein are present in oocytes expressing GK (Fig. 5, $A$ and $B$ ). 


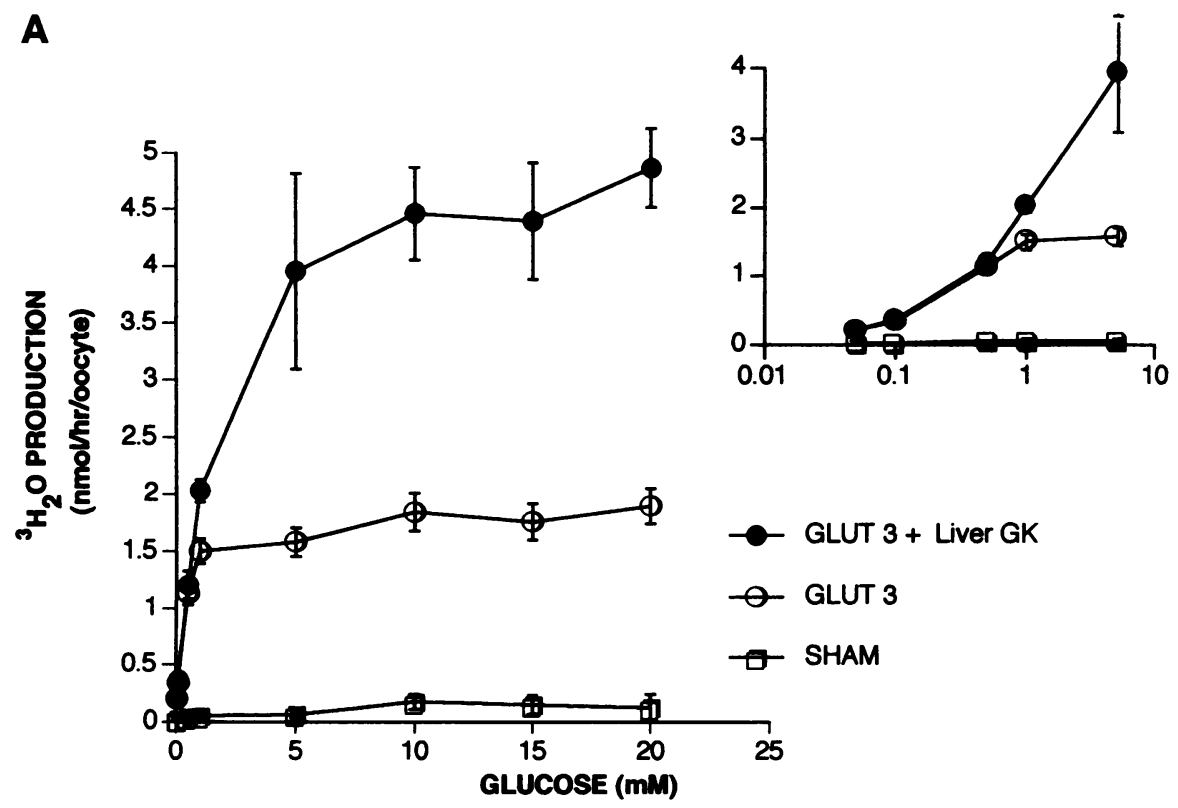

B

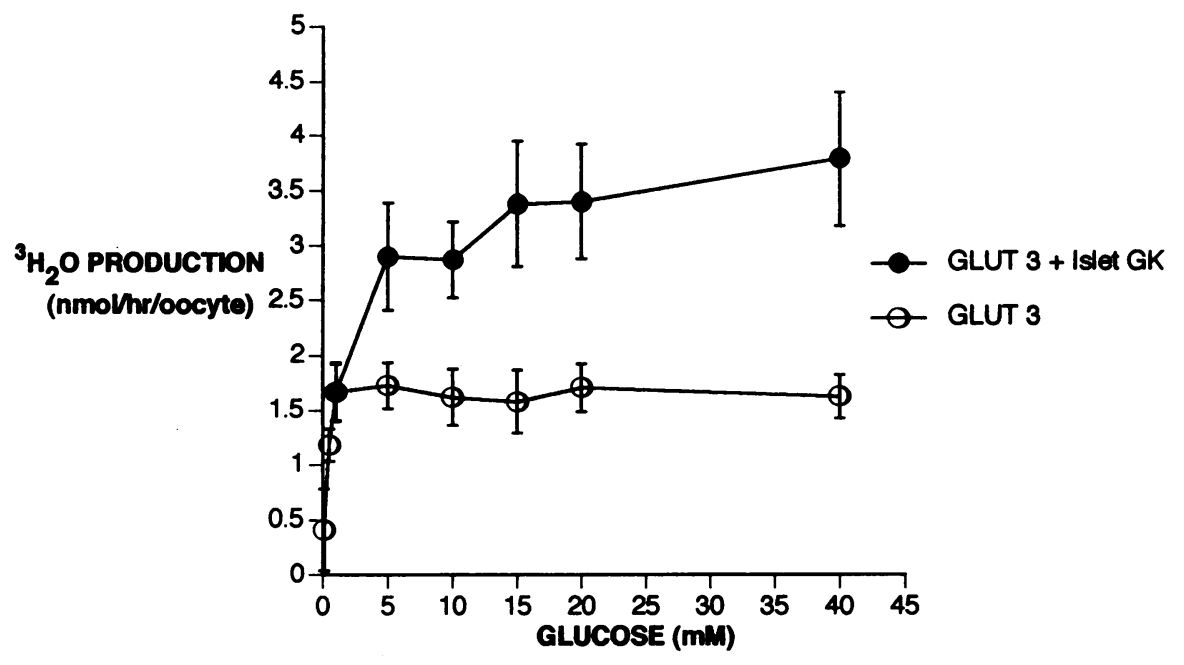

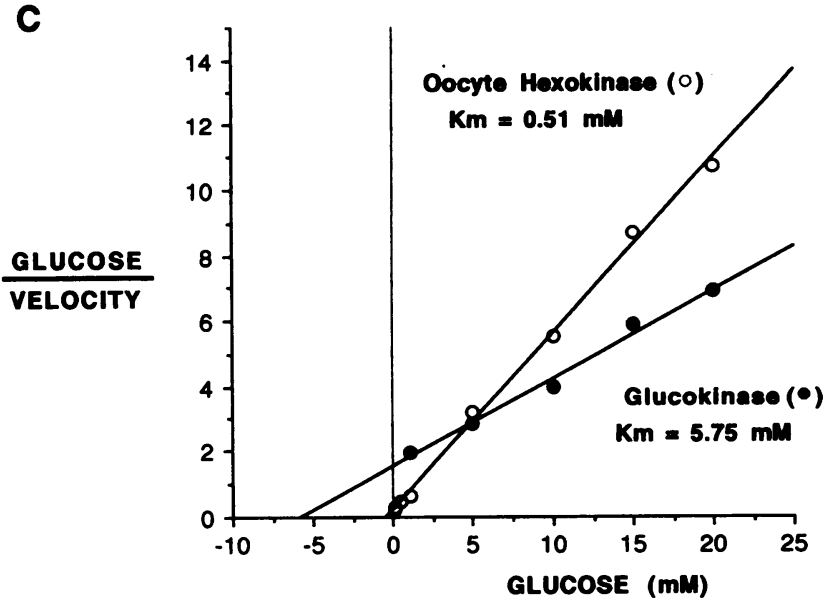

Figure 2. Enzymatic activity of rat liver and human islet GK. (A) Glucose phosphorylating activity $\left({ }^{3} \mathrm{H}_{2} \mathrm{O}\right.$ production rate from $\left[2-{ }^{3} \mathrm{H}\right]$ glucose in nanomoles per hour per oocyte) of oocytes injected with either water (SHAM), GLUT 3, or GLUT 3 and rat liver GK as a function of the extracellular glucose concentration. Data are expressed as the mean activities \pm SEM from three different experiments. The inset shows a magnification of the data points from glucose concentrations $0.05-5 \mathrm{mM}$; the $\mathrm{x}$ axis is a log scale of the glucose concentration and the $y$-axis is identical to the larger figure. $(B)$ Glucose phosphorylating activity as shown in $A$ in oocytes expressing either GLUT 3 alone or GLUT 3 plus human islet GK. (C) Hanes plot of HK activity in intact oocytes (oocytes expressing GLUT 3 alone) and rat liver GK activity (activity of oocytes coexpressing GLUT 3 and GK minus the activity of oocytes expressing GLUT 3 alone) is shown. Each point is the average of at least three separate determinations of the velocity of phosphorylation at that glucose concentration. The $K_{\mathrm{m}}$ for glucose is the $(-\mathrm{X})$ intercept, and the velocity is the 1/slope of the substrate/velocity $(\mathrm{S} / \mathrm{V})$. The correlation coefficient for the oocyte HK and the GK regression is $0.98-0.99$. 


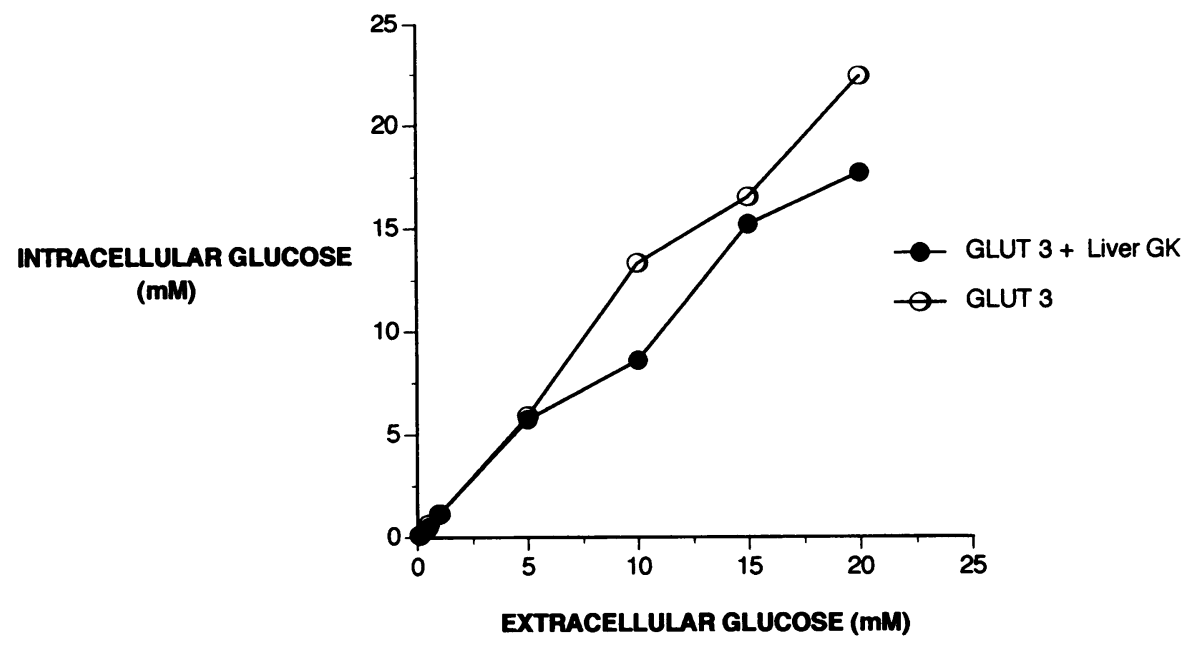

B

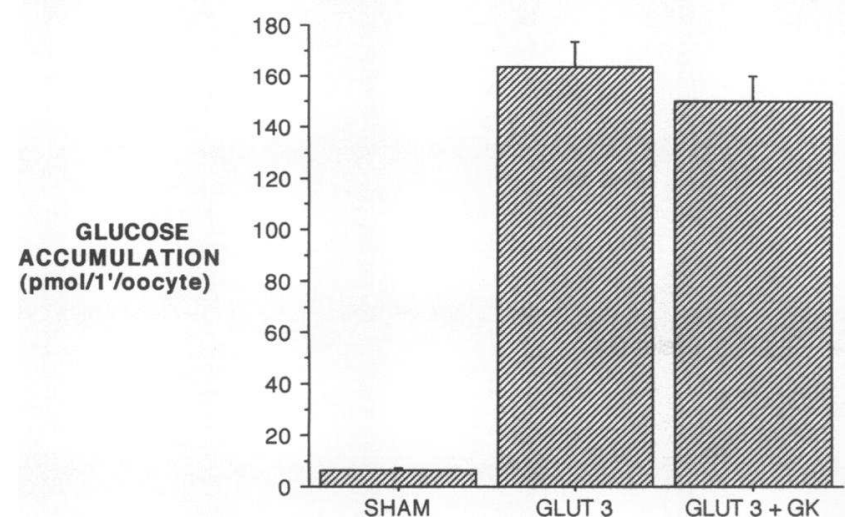

Coexpression of normal and mutant GK. The effect of the coexpression of a mutant and wild-type GK on the function of wild-type human islet GK was also analyzed. Table II shows that oocytes that coexpressed the wild-type human islet GK, the 228:Thr $\rightarrow$ Met mutant, and GLUT 3 had similar kinetics properties for glucose phosphorylation as oocytes expressing the wild-type GK and GLUT 3 only. In addition, oocytes expressing wild-type GK, the 228:Thr $\rightarrow$ Met mutant, and GLUT 2 had similar levels of glucose transport and glucose phosphorylation in the intact oocyte assay as oocytes expressing wild-type GK and GLUT 2 only (Fig. 6, $A$ and $B$ ).

\section{Discussion}

A Xenopus oocyte system was developed to study the independent effects of glucose transporter and GK activity on glucose utilization. Oocytes contain an endogenous, high affinity HK, but glucose utilization in sham-injected oocytes is low, because glucose transport is low and rate-limiting. The expression of GLUT 2 or GLUT 3 increases transport, which results in increased glucose utilization; glucose phosphorylation then becomes the rate-limiting step. The level of glucose utilization is
Figure 3. Measurement of intracellular glucose and glucose transport in oocytes expressing GK and GLUT 3. (A) Intracellular glucose was measured as described in Methods and plotted against the extracellular glucose concentration in oocytes expressing GLUT 3 or GLUT 3 plus rat liver GK. (B) Glucose accumulation was measured by incubating oocytes with 3-O-[ $\left.{ }^{3} \mathrm{H}\right]$ methyl-D-glucose in $1 \mathrm{mM} \mathrm{3-O}$-methyl glucose for $1 \mathrm{~min}$. The results of three experiments in water-injected oocytes (SHAM), oocytes expressing GLUT 3, or GLUT 3 plus rat liver GK are shown (mean \pm SEM). Similar results were obtained with a 30 -min incubation of the glucose tracer.

further increased by coexpression of either the hepatic or islet isoform of GK.

This oocyte system is a physiologically relevant model for analyzing glucose transport and phosphorylation as paired processes since both glucose transporters and GK, when expressed in oocytes, exhibit kinetic properties similar to those in tissues in which they are normally expressed. The affinity for glucose of glucose transporters expressed in oocytes is similar to the tissues in which they are normally expressed $(1,30)$; in the oocyte system, both the hepatic GK and islet GK were found to have an in situ $K_{\mathrm{m}}$ for glucose similar to that found in liver and islet (references 24 and 25 and Table I). In the beta cell, hepatocyte, and GLUT 2- or GLUT 3-expressing oocytes, glucose utilization is limited by the rate of glucose phosphorylation. This is clearly demonstrated using the oocyte system where expression of GK increases glucose utilization two- to threefold at higher glucose concentrations (5-20 mM). Although GLUT 2 and GK are normally coexpressed in the liver and islet, our results indicate that $\mathrm{GK}$ is able to function equivalently with either the high $K_{\mathrm{m}}$ GLUT 2 or low $K_{\mathrm{m}}$ GLUT 3 when transport rates are adequate to equilibrate intracellular and extracellular glucose. This suggests that the velocity of transport may be 
A

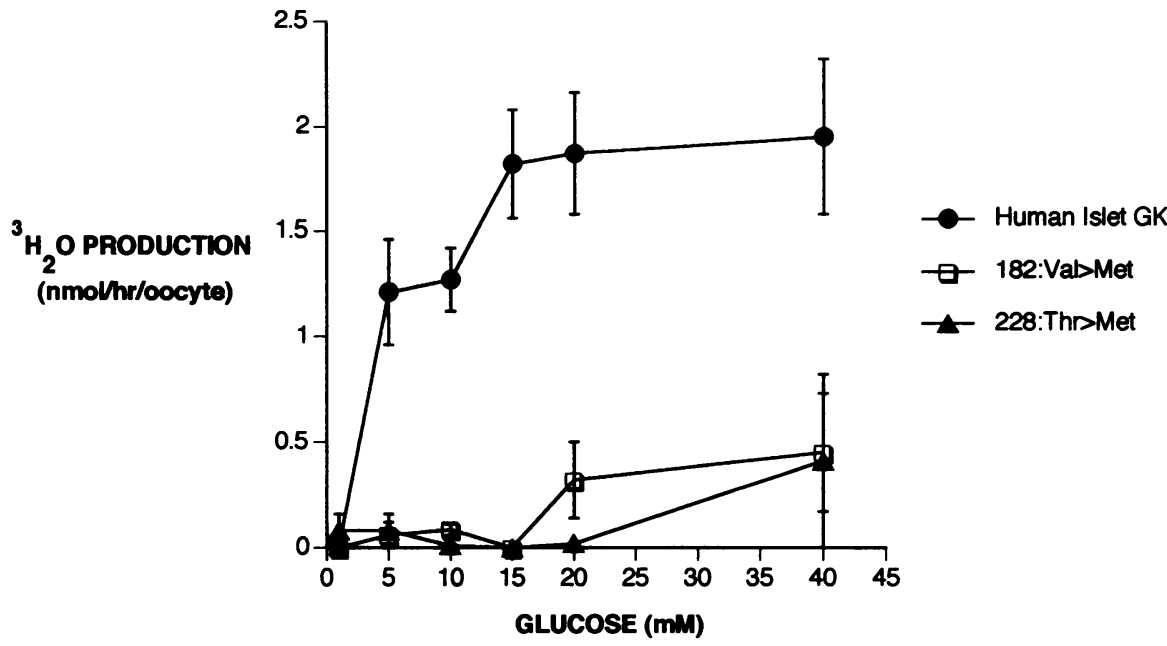

B

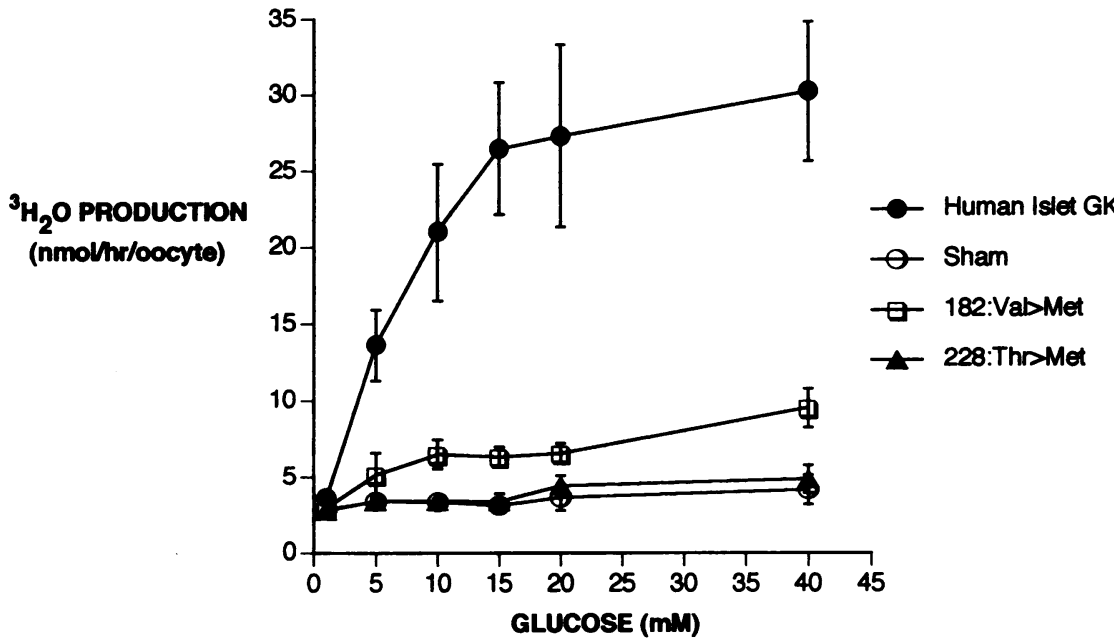

Figure 4. Glucose phosphorylating activity of GK mutants. Glucose phosphorylating activity of wild-type human islet GK and two diabeteslinked GK missense mutations are shown. $(A)$ In the intact oocyte assay, specific GK activity (the activity of oocytes expressing both GLUT 3 and GK minus the activity of oocytes expressing only GLUT 3) is shown for both wild-type human islet GK or GK mutants. (B) Total HK activity in homogenates of oocytes expressing either wild-type human islet GK or mutant GK protein Data are expressed as the mean activity \pm SEM from three experiments.

Table I. Kinetic Analysis of Hexokinase Activity in Intact and Homogenized Oocytes

\begin{tabular}{cccccc}
\hline & \multicolumn{2}{c}{ Intact cell assay } & & \multicolumn{2}{c}{ Homogenate assay } \\
\cline { 2 - 3 } \cline { 5 - 6 } & $V_{\max }^{*}$ & $K_{\mathrm{m}}(\mathrm{mM})^{\ddagger}$ & & $V_{\max }$ & $K_{\mathrm{m}}(\mathrm{mM})$ \\
\hline Oocytes expressing & & & & \\
Endogenous HK & $1.89 \pm 0.17$ & $0.51 \pm 0.12$ & $\mathrm{ND}^{\xi}$ & $\mathrm{ND}$ \\
Rat liver GK & $3.72 \pm 0.19^{\| \prime}$ & $5.75 \pm 1.31^{\| \prime}$ & $\mathrm{NA}^{9}$ & $\mathrm{NA}$ \\
Human islet GK & $2.28 \pm 0.43$ & $8.30 \pm 1.18^{\| \prime}$ & $30.4 \pm 3.60$ & $10.2 \pm 1.79$ \\
Islet GK mutants & & & & \\
182:Val $\rightarrow$ Met & $\mathrm{ND}$ & $\mathrm{ND}$ & $5.22 \pm 1.31^{* *}$ & $13.7 \pm 4.60$ \\
228:Thr $\rightarrow$ Met & $\mathrm{ND}$ & $\mathrm{ND}$ & $\mathrm{ND}$ & $\mathrm{ND}$ \\
300:Glu $\rightarrow$ Lys & $1.92 \pm 0.32$ & $8.86 \pm 2.29 \|$ & $29.5 \pm 3.22$ & $16.3 \pm 0.76^{* *}$ \\
& & & & \\
\hline
\end{tabular}

${ }^{*} V_{\max }$ units are nanomoles of water production/hour/oocyte; ${ }^{\ddagger} K_{\mathrm{m}}$, millimolars of glucose; ${ }^{8} \mathrm{ND}$, not detectable; ${ }^{1} \mathrm{NA}$, not assayed. The values shown are the mean \pm SEM of three to four experiments. $\| P<0.05$ when compared with oocyte $\mathrm{HK}$ in intact cell assay. $* * P<0.05$ when compared with islet GK in homogenate assay.

more important than the $K_{\mathrm{m}}$ of the transporter under such conditions. However, the affinity of the transporter for glucose may influence the phosphorylation rate under conditions in which transport is rate-limiting.

When tested in the oocyte expression system, two diabeteslinked GK mutations exhibited a marked reduction in GK activity. One mutation, GK 182:Val $\rightarrow$ Met, had a markedly reduced $V_{\max }$ for glucose phosphorylation and a slight increase in the $K_{\mathrm{m}}$ for glucose, whereas the GK 228: Thr $\rightarrow$ Met mutation had no detectable enzymatic activity. The amount of GK protein detected $2 \mathrm{~d}$ after the expression of normal and mutant GK in oocytes was similar, thus strongly suggesting that changes in protein synthesis or protein half-life are not important in altering the function of the mutant GK proteins in the beta cell and hepatocyte. The more likely mechanism, as suggested by GidhJain et al. (14), is that the glucose or ATP binding sites of the molecule are affected. The reduced $K_{\mathrm{m}}$ and $V_{\max }$ of these two mutants studied in oocytes were similar to those when these GK mutants were expressed in a prokaryotic system (14).

Matschinsky and co-workers (3) have suggested that a relatively minor reduction in beta cell GK enzyme activity would 

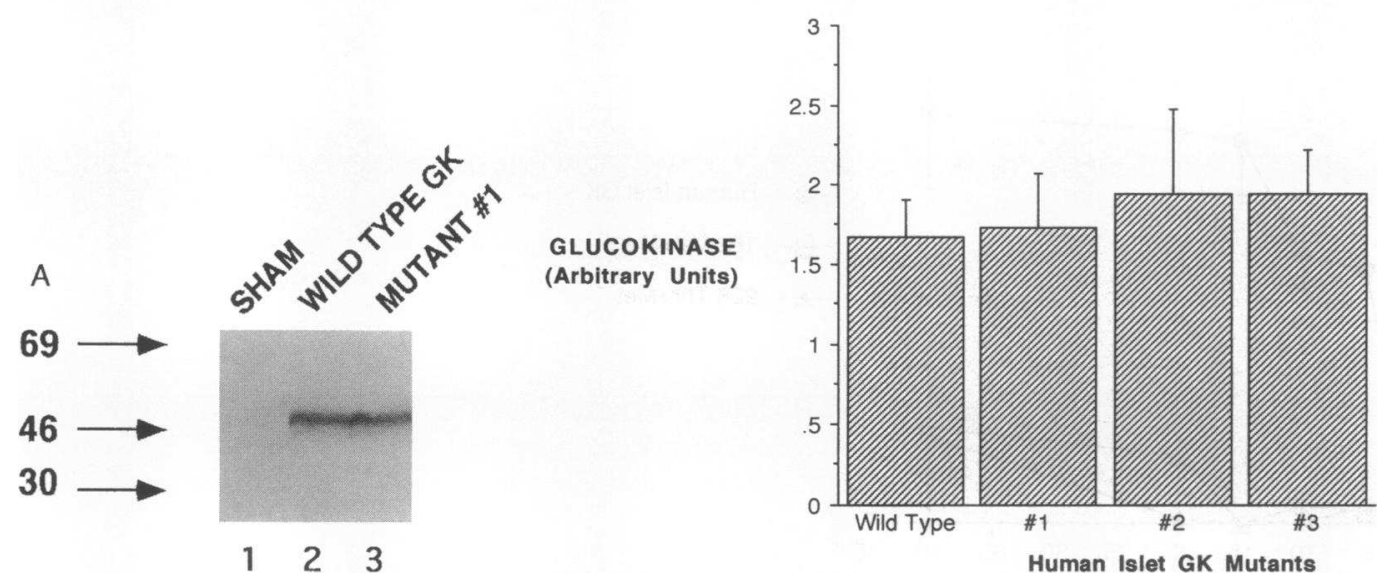

Figure 5. Immunoblot analysis of native and mutant GK protein expression. Oocytes expressing either wild-type or mutant GK protein were homogenized, and the amount of GK protein was determined by immunoblot analysis using a GK antiserum. $(A)$ Photograph of a representative immunoblot of an oocyte extract. Lane 1, uninjected oocyte homogenate; lane 2, wild-type human islet GK; lane 3, GK mutant \#1 (GK 182:Val $\rightarrow$ Met). Molecular mass standards $(\mathrm{kD})$ are indicated on the left of the figure. $(B)$ Densitometric analysis of wild-type GK and mutant GK protein expression from three experiments (mean \pm SEM). Mutant \#1 is GK 182:Val $\rightarrow$ Met, mutant \#2 is GK 228:Thr $\rightarrow$ Met, and mutant \#3 is GK 300:Glu $\rightarrow$ Lys.

sufficiently reduce beta cell glucose metabolism, diminish insulin secretion, and cause diabetes. Such an explanation for diabetes-linked GK mutations must invoke a gene dosage effect and a transcriptional cap on the beta cell GK gene, in that intracellular deficiencies in GK would not be compensated for by increased transcription of the normal GK allele. This agrees with recent evidence that the GK gene is not transcriptionally regulated in the beta cell by extracellular glucose and that changes in GK activity induced by increased extracellular glucose occur at the posttranslational level (22). Since the individuals with MODY are heterozygous for the diabetes-linked GK mutations and the normal GK allele would encode a fully active protein, it is possible that the expression of a mutant protein interferes with function of the normal GK protein and thus further reduces the glucose phosphorylating activity in the beta cell. Our finding that wild-type GK protein coexpressed with a mutant GK protein with no enzymatic activity had the glucose phosphorylating activity expected of wild-type GK protein alone strongly argues against such a dominant negative effect and for a gene dosage effect. All GK mutations detected thus far are present in a portion of the gene that is common to both the islet and hepatic GK isoforms, but little is known about hepatic glucose utilization in individuals with MODY. Since GK gene expression in the liver is positively regulated by insulin (31), the decreased

Table II. Coexpression of a Mutant GK Does Not Interfere with Activity of the Normal Enzyme

\begin{tabular}{lll}
\hline & $V_{\max }{ }^{*}$ & $K_{\mathrm{m}}(\mathrm{mM})^{\ddagger}$ \\
\hline Human islet GK & $2.1,2.5$ & $8.5,9.3$ \\
Islet GK + mutant GK & $2.3,3.3$ & $6.4,10.4$ \\
\hline
\end{tabular}

${ }^{*} V_{\max }$ units are nanomoles of water production/hour/oocyte; ${ }^{\ddagger} K_{\mathrm{m}}$, millimolars of glucose; ${ }^{8}$ Human islet mutant is GK 228:Thr $\rightarrow$ Met. Kinetic parameters (results of two experiments) were derived as described in Fig. 1. Glucose transporter is GLUT 3. insulin levels as a result of the islet GK mutation and a mutation in hepatic GK protein may combine to also reduce glucose utilization in the liver.

Of interest, the GK 300:Glu $\rightarrow$ Lys mutation had a similar $V_{\max }$ and $K_{\mathrm{m}}$ in the intact oocyte system and a similar $V_{\max }$ and only a small increase in its $K_{\mathrm{m}}$ in the oocyte homogenate assay when compared with the wild-type GK protein. Our results with this mutation differ from those reported by Gidh-Jain et al. (14) who found a $V_{\max }$ of $33 \%$ of wild-type and a higher $K_{\mathrm{m}}$ for glucose $(25 \mathrm{mM})$. These slight differences may relate to the expression of GK in a eukaryotic system rather than the prokaryotic system used by Gidh-Jain et al. (14). However, both studies demonstrate that this diabetes-linked mutation possesses substantial enzymatic activity, which suggests that a reduction in glucose phosphorylation is not the etiology of the diabetes and that an alternative mechanism may be operable. This raises the possibility that some GK mutations reduce insulin secretion by a mechanism unrelated to their reduction in glucose phosphorylation. Correlation of the clinical findings (degree of hyperglycemia and insulin secretory capacity) in families with this mutation and the clinical picture in families with mutations that completely lack enzyme activity will be important. A recent report demonstrated an overall correlation of in vitro GK enzymatic activity with the insulin secretion rate in subjects with GK mutations, but one individual with a GK mutation that almost completely inactivated the enzyme in vitro had the highest insulin secretion rate (32).

The present study has established the utility of the Xenopus oocyte system to study the functional pairing of glucose transport and phosphorylation by coexpression of glucose transporters and hexokinases. The oocyte system allows for the study of a process dependent on the interaction of a transmembrane protein and a cytoplasmic protein and may be applicable to the study of other cellular processes. This system can also be used to examine glucose utilization as the level of transport and phosphorylation is varied by the amount of RNA injected and to address whether coexpression of a certain HK with a specific 


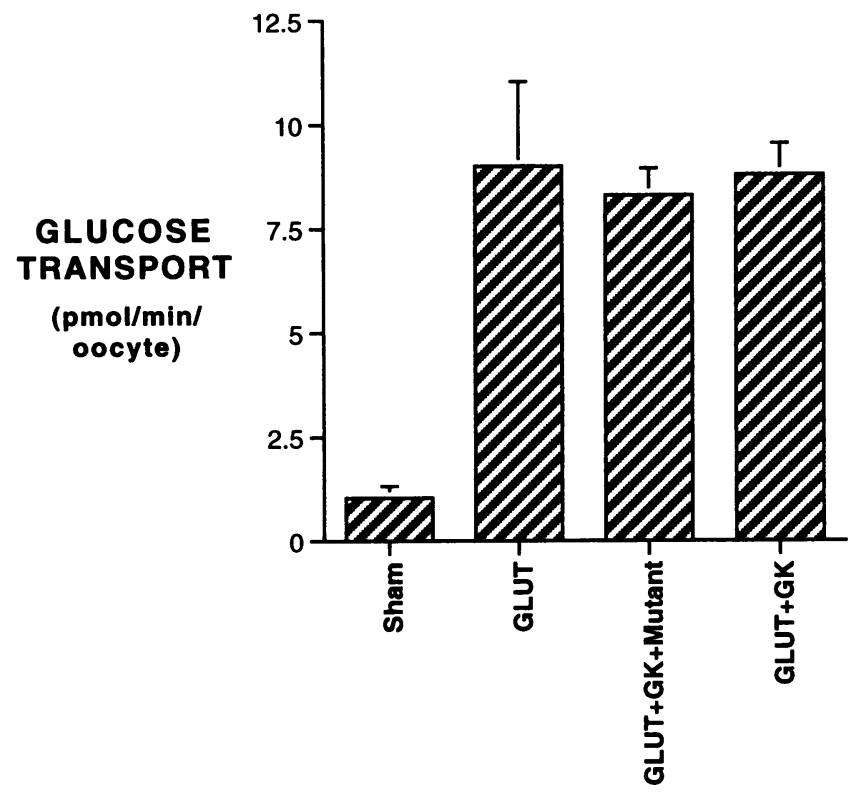

B

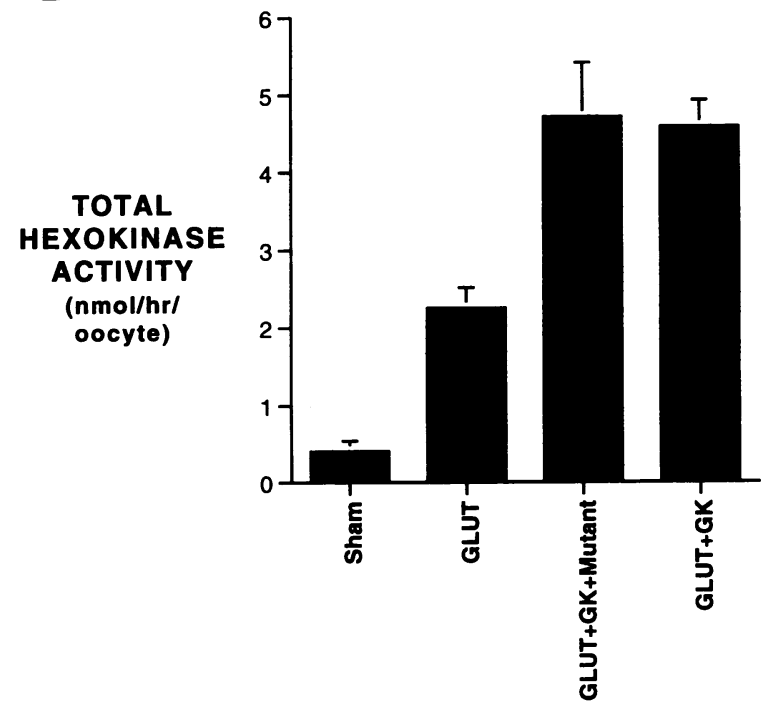

Figure 6. Coexpression of mutant GK with wild-type GK does not influence glucose transport or phosphorylation. Sham-injected oocytes, oocytes expressing GLUT 3 alone (GLUT), oocytes expressing GLUT 2, wild-type GK, and 228:Thr $\rightarrow$ Met GK mutant $(G L U T+G K+M u$ tant), or oocytes expressing GLUT 2 and wild-type GK $(G L U T+G K)$ were analyzed for glucose transport and glucose phosphorylation. Each panel represents the mean \pm SEM of 3 experiments with 10 oocytes/ experiment. $(A)$ The accumulation of $3-O-\left[{ }^{3} \mathrm{H}\right]$ methyl-D-glucose $(1 \mathrm{mM})$ by oocytes was measured after a 30 -min incubation as described in Fig. 1. (B) Total glucose phosphorylating activity $\left({ }^{3} \mathrm{H}_{2} \mathrm{O}\right.$ production rate from $\left[2-{ }^{3} \mathrm{H}\right]$ glucose in nanomoles/hour/oocyte) in the intact oocyte assay was measured at $20 \mathrm{mM}$ glucose as described in Fig. 1.

transporter affects the rate of glucose utilization. In this study, we demonstrate that both glucose transporter (either GLUT 2 or GLUT 3) and GK activity are important in glucose utilization. In addition, GK is responsible for the increased glucose utilization in this system at physiologic glucose concentrations greater than $1 \mathrm{mM}$.

\section{Acknowledgments}

These studies were supported by grants from the National Institutes of Health (DK-43736 to A. C. Powers, DK-42612 to M. A. Magnuson, DK-38794 to J. M. May, DK-35107 to D. K. Granner, and DK-42502 to D. K. Granner and M. A. Magnuson), by Career Development Awards from the Department of Veterans Affairs Research Service and the American Diabetes Association (A. C. Powers), a University Grant from Vanderbilt University, and a BRSG grant administered by Vanderbilt University (BRSG RR05424).

\section{References}

1. Thorens, B. 1993. Facilitated glucose transporters in epithelial cells. Annu. Rev. Physiol. 55:591-608.

2. Purich, D. L., H. J. Fromm, and F. B. Rudolph. 1973. The hexokinases: kinetic, physical, and regulatory properties. Adv. Enzymol. Relat. Areas Mol. Biol. 39:249-326.

3. Matschinsky, F. M. 1990. Glucokinase as glucose sensor and metabolic signal generator in pancreatic beta-cells and hepatocytes. Diabetes. 39:647-652

4. Kahn, B. B., and J. S. Flier. 1990. Regulation of glucose-transporter gene expression in vitro and in vivo. Diabetes Care. 13:548-564.

5. Newgard, C. B., C. Quaade, S. D. Hughes, and J. L. Milburn. 1990. Glucokinase and glucose transporter expression in liver and islets: implications for control of glucose homeostasis. Biochem. Soc. Trans. 18:851-853.

6. Meglasson, M. D., and F. M. Matschinsky. 1984. New perspectives on pancreatic islet glucokinase. Am. J. Physiol. 246:E1-E13.

7. Fajans, S. S., G. I. Bell, and D. W. Bowden. 1992. MODY: a model for the study of the molecular genetics of NIDDM. J. Lab. Clin. Med. 119:206-210.

8. Froguel, P., M. Vaxillaire, F. Sun, G. Velho, H. Zouali, M. O. Butel, S. Lesage, N. Vionnet, K. Clement, F. Fougerousse, et al. 1992. Close linkage of glucokinase locus on chromosome $7 p$ to early-onset non-insulin-dependent diabetes mellitus. Nature (Lond.). 356:162-164.

9. Vionnet, N., M. Stoffel, J. Takeda, K. Yasuda, G. I. Bell, H. Zouali, S. Lesage, G. Velho, F. Iris, P. Passa, et al. 1992. Nonsense mutation in the glucokinase gene causes early-onset non-insulin-dependent diabetes mellitus. Nature (Lond.). 356:721-722.

10. Stoffel, M., P. Froguel, J. Takeda, H. Zouali, N. Vionnet, S. Nishi, I. T. Weber, R. W. Harrison, S. J. Pilkis, S. Lesage, et al. 1992. Human glucokinase gene: isolation, characterization, and identification of two missense mutations linked to early-onset non-insulin-dependent (type 2) diabetes mellitus. Proc. Natl. Acad. Sci. USA. 89:7698-7702.

11. Permutt, M. A., K. C. Chiu, and Y. Tanizawa. 1992. Glucokinase and NIDDM. A candidate gene that paid off. Diabetes. 41:1367-1372.

12. Hattersley, A. T., R. C. Turner, M. A. Permutt, P. Patel, Y. Tanizawa, K. C. Chiu, S. O'Rahilly, P. J. Watkins, and J. S. Wainscoat. 1992. Linkage of type 2 diabetes to the glucokinase gene. Lancet. 339:1307-1310.

13. Velho, G., P. Froguel, K. Clement, M. E. Pueyo, B. Rakotoambinina, H Zouali, P. Passa, D. Cohen, and J. J. Robert. 1992. Primary pancreatic beta-cell secretory defect caused by mutations. Lancet. 340:444-448.

14. Gidh-Jain, M., J. Takeda, L. Z. Xu, A. J. Lange, N. Vionnet, M. Stoffel, P. Froguel, G. Velho, F. Sun, D. Cohen, et al. 1993. Glucokinase mutations associated with non-insulin-dependent (type 2) diabetes mellitus have decreased enzymatic activity: implications for structure/function relationships. Proc. Natl. Acad. Sci. USA. 90:1932-1936.

15. Unger, R. H. 1991. Diabetic hyperglycemia: link to impaired glucose transport in pancreatic beta cells. Science (Wash. DC). 251:1200-1205.

16. Andreone, T. L., R. L. Printz, S. J. Pilkis, M. A. Magnuson, and D. K. Granner. 1989. The amino acid sequence of rat liver glucokinase deduced from cloned cDNA. J. Biol. Chem. 263:363-369.

17. Tanizawa, Y., A. Matsutani, K. C. Chiu, and M. A. Permutt. 1992. Human glucokinase gene: isolation, structural characterization, and identification of a microsatellite repeat polymorphism. Mol. Endocrinol. 6:1070-1081.

18. Kunkel, T. A., K. Bebenek, and J. McClary. 1991. Efficient site-directed mutagenesis using uracil-containing DNA. Methods Enzymol. 204:125-139.

19. Hammerstedt, R. H. 1973. The use of Dowex-1-borate to separate $3 \mathrm{HOH}$ from 2-3H-glucose. Anal. Biochem. 56:292-293.

20. Katz, J., and R. Rognstad. 1969. The metabolism of glucose-2-T by adipose tissue. J. Biol. Chem. 244:99-106.

21. Whitesell, R. R., M. K. Aboumrad, A. C. Powers, D. M. Regen, C. Le, J. M. Beechem, J. M. May, and N. A. Abumrad. 1993. Coupling of glucose transport and phosphorylation in Xenopus oocytes and cultured cells: determination of the rate-limiting step. J. Cell. Physiol. 157:509-513.

22. Liang, Y., H. Najafi, R. M. Smith, E. C. Zimmerman, M. A. Magnuson, M. Tal, and F. M. Matschinsky. 1992. Concordant glucose induction of glucokinase, glucose usage, and glucose-stimulated insulin release in pancreatic islets maintained in organ culture. Diabetes. 41:792-806. 
23. Jetton, T. L., and M. A. Magnuson. 1992. Heterogeneous expression of glucokinase among pancreatic beta cells. Proc. Natl. Acad. Sci. USA. 89:26192623.

24. Quaade, C., S. D. Hughes, W. S. Coats, A. L. Sestak, P. B. Iynedjian, and C. B. Newgard. 1991. Analysis of the protein products encoded by variant glucokinase transcripts via expression in bacteria. FEBS (Fed. Eur. Biochem. Soc.) Lett. 280:47-52.

25. Liang, Y., T. L. Jetton, E. C. Zimmerman, H. Najafi, F. M. Matschinsky, and M. A. Magnuson. 1991. Effects of alternate RNA splicing on glucokinase isoform activities in the pancreatic islet, liver, and pituitary. J. Biol. Chem. 266:6999-7007.

26. Meglasson, M. D., and F. M. Matschinsky. 1986. Pancreatic islet glucose metabolism and regulation of insulin secretion. Diabetes Metab. Rev. 2:163-214.

27. Trus, M. D., K. C. Zawalich, P. T. Burch, D. K. Berner, V. A. Weill, and

F. M. Matschinsky. 1981. Regulation of glucose metabolism in pancreatic islets. Diabetes. 30:911-922.

28. Nishimura, H., F. V. Pallardo, G. A. Seidner, S. Vannucci, I. A. Simpson, and M. J. Birnbaum. 1993. Kinetics of GLUT1 and GLUT4 glucose transporters expressed in Xenopus oocytes. J. Biol. Chem. 268:8514-8520.

29. Garcia, J. C., M. Strube, K. Leingang, K. Keller, and M. M. Mueckler. 1992. Amino acid substitutions at tryptophan 388 and tryptophan 412 of the HepG2 (Glut1) glucose transporter inhibit transport activity and targeting to the plasma membrane in Xenopus oocytes. J. Biol. Chem. 267:7770-7776.

30. Gould, G. W., H. M. Thomas, T. J. Jess, and G. I. Bell. 1991. Expression of human glucose transporters in Xenopus oocytes: kinetic characterization and substrate specificities of the erythrocyte, liver, and brain isoforms. Biochemistry. 30:5139-5145.

31. Magnuson, M. A., T. L. Andreone, R. L. Printz, S. Koch, and D. K. Granner. 1989. Rat glucokinase gene: structure and regulation by insulin. Proc. Natl. Acad. Sci. USA. 86:4838-4842.

32. Byrne, M. M., J. Sturis, K. Clément, N. Vionnet, M. E. Pueyo, M. Stoffel, J. Takeda, P. Passa, D. Cohen, G. I. Bell, et al. 1994. Insulin secretory abnormalities in subjects with hyperglycemia due to glucokinase mutations. J. Clin. Invest. 93:1120-1130. 